
\title{
3 Research Square \\ Risk Factors for Postoperative Recurrence of Ovarian Endometrioma in Young Women
}

\section{Xing Xin}

Shengjing Hospital of China Medical University

\section{Xiaochen Song}

Peking Union Medical College Hospital Department of Obstetrics and Gynecology

\section{Xinyang Zhao}

Shengjing Hospital of China Medical University

\section{Shanshan WU}

Shengjing Hospital of China Medical University

\section{Xinyao Hao}

Shengjing Hospital of China Medical University

\section{Aixin Song}

Shengjing Hospital of China Medical University

\section{Zifan Meng}

Shengjing Hospital of China Medical University

Jiarui Qi

Shengjing Hospital of China Medical University

Jichun Tan ( $\nabla$ tjczjh@163.com )

Shengjing Hospital of China Medical University https://orcid.org/0000-0002-6401-1919

\section{Research}

Keywords: ovarian endometrioma, recurrence, risk factors, young women

Posted Date: May 4th, 2021

DOI: https://doi.org/10.21203/rs.3.rs-449055/v1

License: (c) (1) This work is licensed under a Creative Commons Attribution 4.0 International License. Read Full License 


\section{Abstract}

Background: Ovarian endometroma seriously affects women's health, and is susceptible to recurrence after surgery. However, only a few studies have been conducted to asses the risk factors for postoperative recurrence of ovarian endometrioma in young women, and no risk factors associated with recurrence have been found. The purpose of this study is to analyse the risk factors for postoperative recurrence of ovarian endometrioma in young women.

Materials and Methods: We retrospectively analysed 196 young women who underwent ovarian endometrioma resection in Peking Union Medical College Hospital and Shengjing Hospital from January 2008 to January 2018 and were followed-up for at least 3 years postoperatively. The patients were divided into a recurrence group or a non-recurrence group. Their preoperative histories, laboratory indexes, intraoperative manifestations, and follow-up symptoms were analysed.

Results: The cumulative recurrence rate of ovarian endometrioma in young women 3 and 5 years after surgery was $8.0 \%$, and $20.3 \%$, respectively. Univariate analysis showed significant differences in cancer antigen-125 levels (hazard ratio [HR]: $3.207,95 \%$ confidence interval [Cl]: $1.126-9.135, P=0.029$ ), the revised American Fertility Society (rAFS) disease stage (HR: 4.588, 95\%Cl: 1.422-14.805, P =0.011), postoperative pregnancy (HR: $0.28,95 \% \mathrm{Cl}: 0.109-0.723, \mathrm{P}=0.008)$, and postoperative dysmenorrhoea (HR: $2.465,95 \% \mathrm{Cl}: 1.320-4.604, \mathrm{P}=0.005$ ) between the two groups. Cox multivariate proportional risk analysis showed that rAFS disease stage (HR:3.783, 95\%Cl: $1.162-12.311, \mathrm{P}=0.027)$ and postoperative dysmenorrhoea (HR: $2.291,95 \% \mathrm{Cl}: 1.222-4.296, \mathrm{P}=0.01$ ) were risk factors for postoperative recurrence of ovarian endometrioma, whereas postoperative pregnancy (HR: $0.361,95 \% \mathrm{Cl}: 0.138-0.944, \mathrm{P}=0.038$ ) was a protective factor for postoperative recurrence. There was no significant correlation between recurrence of ovarian endometrioma and age at surgery, age at the time of menarche, body mass index, duration of dysmenorrhoea, degree of dysmenorrhoea, genital malformation, surgical approach, maximum diameter of the cyst, and postoperative medication.

Conclusion: rAFS disease stage and postoperative dysmenorrhoea are risk factors for the recurrence of ovarian endometrioma during long-term follow-up, whereas postoperative pregnancy is a protective factor.

\section{Introduction}

Endometriosis is a disease caused by the presence of endometrial tissue outside the uterine body. Although it is an oestrogen-dependent benign disease, it is characterised by implantation, invasion, and distant metastasis, which are features similar to those of malignant tumours. Patients with mild endometriosis can be treated with prophylactic therapy or medication. However, if the patient does not experience symptomatic relief after medication and the local lesion exacerbates, surgery is needed. Since this disease mostly occurs in women of childbearing age who have fertility requirements, conservative surgery is the first choice of treatment. However, postoperative recurrence has become one of the 
challenges in the clinical treatment of this disease. In a comprehensive analysis of 23 studies, author estimated the recurrence rate of endometriosis in adult women after primary surgery to be $21.5 \%$ within 2 years and $40.0-50.0 \%$ within 5 years [1]. In a multicentre retrospective cohort study of 105 adolescent women younger than 20 years old, Lee reported cumulative recurrence rates of $10 \%$ and $19.9 \%$ at 3 and 5 years, respectively; however, the analysis of the results did not identify risk factors for recurrence [2]. Only a few studies have been conducted to analyse the risk factors for postoperative recurrence of ovarian endometrioma in young women. Therefore, the purpose of this study was to evaluate the frequency of clinical recurrence in young women who underwent conservative surgery for ovarian endometrioma, and to explore the risk factors for postoperative recurrence of the disease.

\section{Materials And Methods Study population}

We retrospectively evaluated 196 young female patients who underwent ovarian endometrioma resection in Peking Union Medical College Hospital and Shengjing Hospital between January 2008 and January 2018. They were followed-up for at least 3 years, from the date of surgery to the date of last follow-up and the follow-up time was measured in months; the study ended in January 2021. The inclusion criteria were as follows: (1) ovarian endometriosis confirmed through pathological assessment, (2) age $\leq$ 21 years old, and (3) follow-up duration of at least 3 years. The exclusion criteria were as follows: (1) prior surgery for ovarian endometriosis, (2) incomplete preoperative data, and (3) ovarian endometriosis complicated with malignant or borderline tumours. All patients provided informed consent prior to surgery.This study was approved by the Ethics Committee of Peking Union Medical College Hospital and Shengjing Hospital.

\section{Methods}

This was a retrospective case control study. Consultation, pathography, telephone follow-up, and outpatient appointments were conducted for each patient and the following clinical data were collected: age at the time of surgery, body mass index (BMI), age at the time of menarche, dysmenorrhoea score, duration of dysmenorrhoea, serum cancer antigen 125 (CA125) level, surgical approach, the revised American Fertility Society (rAFS) disease stage, genital malformation, maximum diameter of ovarian endometrioma, postoperative pregnancy, postoperative dysmenorrhoea, postoperative medication, and duration from time of surgery to recurrence. Each surgery was performed by an experienced gynaecologist with expertise in the assessment and treatment of endometriosis. Pain was scored based on the $10 \mathrm{~cm}$ visual analogue scale, and pain intensity was classified as none (0), mild (1-4), moderate $(5-7)$, or severe (8-10). The threshold points for defining the severity of pain were chosen based on previous correlation analyses [3]. Disease stages were classified according to the rAFS classification system (1996) [4]. Recurrent endometrioma was defined as the presence of a persistent ovarian cyst with a minimum diameter of $2 \mathrm{~cm}$, thick walls, regular margins, and a homogenous low echogenic fluid 
content with scattered internal echoes [5]. If the cyst is indistinguishable from a transient luteal cyst or a haemorrhagic cyst, recurrence may be diagnosed only if the cyst persists after several successive menstrual cycles.

\section{Statistical analysis}

Statistical analysis was performed using the Statistic Package for Social Sciences 26.0 (SPSS Inc., Chicago, IL, USA). The Shapiro-Wilk test was used to test whether the measurement data complied with the normal distribution. The measurement data that conformed to the normal distribution were expressed as means \pm standard deviations; the independent t-test was used for comparison between groups. The measurement data that did not follow the normal distribution were represented as medians (first quartile to third quartile); the comparison between groups was performed using the Wilcoxon rank sum test. Enumeration data were presented as cases (percentages) using either Fisher's exact test or the chi-square test. The Kaplan-Meier curve was used to describe the survival changes, and log-rank test was used to compare the differences between survival curves. Univariate analysis was used to identify potential risk factors $(P<0.1)$. In multivariate analysis, if the assumption of equal proportional risk was satisfied, Cox proportional hazard regression model was used to study the influence of factors on survival; if the equal proportional risk assumption was not satisfied, the stratified variable control was used. Hazard ratio (HR) and $95 \%$ confidence intervals $(\mathrm{Cl})$ were calculated as measures of recurrence risk in each study. Significance was defined as $\mathrm{P}<0.05$.

\section{Results}

A total of 196 patients with ovarian endometrioma were enrolled in this study. The median age of the patients at the time of surgery was 20 years (18-21 years), the mean BMI was $20.93 \pm 2.95 \mathrm{Kg} / \mathrm{m}^{2}$, the median age at the time of menarche was 13 years (12-13.75 years), the median duration of dysmenorrhoea was 5 months (1-12 months), and the median CA125 level was $65 \mathrm{U} / \mathrm{ml}(34-128 \mathrm{U} / \mathrm{ml})$. Thirty-three patients $(16.8 \%)$ had dysmenorrhoea before surgery, 45 patients $(23 \%)$ had mild dysmenorrhoea, 70 patients $(35.7 \%$ ) had moderate dysmenorrhoea, and 48 patients $(24.5 \%)$ had severe dysmenorrhoea. Forty patients $(20.4 \%)$ had genital malformation, and the median maximum diameter of ovarian endometrioma was $7.3 \mathrm{~cm}(5.6-9.3 \mathrm{~cm})$. Regarding the rAFS disease stages, 38 patients $(19.4 \%)$ had stages I-II disease, whereas 158 patients (80.6\%) had stages III-IV. Regarding the patients' choice of postoperative treatment drugs, 46 patients (23.5\%) did not receive medication, 111 patients $(56.6 \%)$ received gonadotropin-releasing hormone agonists (GnRH-a) for 3-6 months, 20 patients $(10.2 \%)$ received oral short-acting contraceptives for at least 6 months, 17 patients $(8.7 \%)$ received $\mathrm{GnRH}-\mathrm{a}$ combined with oral short-acting contraceptives, and two patients (1\%) received gestrinone for 6 months. Thirty-two patients (16.3\%) were pregnant after surgery.

After at least 3 years of postoperative follow-up (median, 55 months [ $40-81$ months]), the cumulative recurrence rate of ovarian endometrioma was $8.0 \%$ at 3 years and $20.3 \%$ at 5 years. The clinical characteristics of the patients with ovarian endometrioma in the non-recurrence and the recurrence 
groups are shown in Table 1. There were significant differences in rAFS disease stage and postoperative dysmenorrhoea between the two groups. 
Table 1

Baseline characteristics of nonrecurrent and recurrent ovarian endometrioma

\begin{tabular}{|c|c|c|c|c|}
\hline Variables & $\begin{array}{l}\text { Nonrecurrence } \\
\text { group } \\
(n=148)\end{array}$ & $\begin{array}{l}\text { Recurrence } \\
\text { group } \\
(n=48)\end{array}$ & $\begin{array}{l}\text { Statistical } \\
\text { values }\end{array}$ & $\begin{array}{l}\mathrm{P} \\
\text { Value }\end{array}$ \\
\hline $\begin{array}{l}\text { Age, years, median (first quartile - third } \\
\text { quartile) }\end{array}$ & $20(18-21)$ & $\begin{array}{l}20(18.25- \\
20.75)\end{array}$ & $-0.265^{\|}$ & 0.791 \\
\hline BMI (mean \pm SD) & $21.12 \pm 3.05$ & $20.27 \pm 2.51$ & $1.593^{\ddagger}$ & 0.113 \\
\hline $\begin{array}{l}\text { Menarche age, years, median (first quartile } \\
\text { - third quartile) }\end{array}$ & $13(12-14)$ & $13(12-13)$ & $-0.221^{\|}$ & 0.825 \\
\hline $\begin{array}{l}\text { CA-125 (U/ml), median (first quartile - third } \\
\text { quartile) }\end{array}$ & $\begin{array}{l}61.15(31.61- \\
128.00)\end{array}$ & $\begin{array}{l}72.75(48.53- \\
130.03)\end{array}$ & $-1.122^{\|}$ & 0.262 \\
\hline Preoperative dysmenorrhoea, $\mathrm{n}(\%)$ & $121(81.8)$ & $42(87.5)$ & $0.854 \S$ & 0.355 \\
\hline $\begin{array}{l}\text { Duration of dysmenorrhoea,months, median } \\
\text { (first quartile - third quartile) }\end{array}$ & $5(0.5-12)$ & $5(2-18)$ & $-0.267^{\|}$ & 0.789 \\
\hline Extent of dysmenorrhoea, n (\%) & & & $4.469 \S$ & 0.215 \\
\hline None & $27(18.2)$ & $6(12.5)$ & & \\
\hline Mild & $38(25.7)$ & $7(14.6)$ & & \\
\hline Moderate & $50(33.8)$ & $20(41.7)$ & & \\
\hline Severe & $33(22.3)$ & 15(31.3) & & \\
\hline Surgical approach, n (\%) & & & $0.007 \S$ & 0.932 \\
\hline Laparoscope & 133(89.9) & $44(91.7)$ & & \\
\hline Laparotomy & 15(10.1) & $4(8.3)$ & & \\
\hline Genital malformation, n (\%) & $34(23.0)$ & $6(12.5)$ & $2.447 \S$ & 0.118 \\
\hline rAFS, n (\%) & & & $7.020 \S$ & 0.008 \\
\hline $\mid-\|$ & $35(23.6)$ & $3(6.3)$ & & \\
\hline III-IV & $113(76.4)$ & $45(93.8)$ & & \\
\hline Cyst diameter $(\mathrm{cm})$ & 7.3(5.6-9.3) & $7.1(5.5-8.9)$ & $-0.348 \|$ & 0.728 \\
\hline Postoperative dysmenorrhoea, n (\%) & $64(43.2)$ & $34(70.8)$ & $11.036 \S$ & $<.001$ \\
\hline Postoperative pregnancy, n (\%) & $27(18.2)$ & $5(10.4)$ & $1.625^{\S}$ & 0.202 \\
\hline
\end{tabular}




\begin{tabular}{|c|c|c|c|c|}
\hline Variables & $\begin{array}{l}\text { Nonrecurrence } \\
\text { group } \\
(n=148)\end{array}$ & $\begin{array}{l}\text { Recurrence } \\
\text { group } \\
(n=48)\end{array}$ & $\begin{array}{l}\text { Statistical } \\
\text { values }\end{array}$ & $\begin{array}{l}\mathrm{P} \\
\text { Value }\end{array}$ \\
\hline Postoperative medication, n (\%) & & & $3.283^{\S}$ & 0.486 \\
\hline None & $35(23.6)$ & $11(22.9)$ & & \\
\hline GnRH-a & $87(58.8)$ & $24(50.0)$ & & \\
\hline OCP & $13(8.8)$ & 7(14.6) & & \\
\hline Gestrinone & $1(0.7)$ & $1(2.1)$ & & \\
\hline GnRH-a with OCP & 12(8.1) & $5(10.4)$ & & \\
\hline \multicolumn{5}{|c|}{$\begin{array}{l}\text { Abbreviations: BMI Body mass index, CA-125 Cancer antigen } 125 \text {, cm centimeter, GnRHa } \\
\text { Gonadotropin-releasing hormone agonist, OCP Oral contraceptive pills, rAFS Revised American } \\
\text { Fertility Society classification system, } \neq_{t} \text { t values, } \$ \chi^{2} \text { values, "Z values. }\end{array}$} \\
\hline
\end{tabular}

A cox regression model was used to conduct univariate analysis of risk factors for postoperative recurrence among the enrolled patients. The recurrence group and non-recurrence group showed significant differences in CA125 level (HR: $3.207,95 \% \mathrm{Cl}$ : 1.126-9.135, $\mathrm{P}=0.029)$, rAFS disease stage (HR: $4.588,95 \% \mathrm{Cl}: 1.422-14.805, \mathrm{P}=0.011$ ), postoperative pregnancy (HR: $0.28,95 \% \mathrm{Cl}: 0.109-0.723, \mathrm{P}$ $=0.008)$, and postoperative dysmenorrhoea (HR: 2.465, 95\% Cl:1.320-4.604, $\mathrm{P}=0.005)$. The recurrence of ovarian endometrioma was not significantly correlated with age at the time of surgery, age at the time of menarche, duration of dysmenorrhoea, degree of dysmenorrhoea, genital malformation, maximum cyst diameter, and postoperative medication. Cox multivariate proportional risk analysis showed that rAFS disease stage (HR:3.783, 95\% Cl: $1.162-12.311, \mathrm{P}=0.027$ ) and postoperative dysmenorrhoea (HR: $2.291,95 \% \mathrm{Cl}: 1.222-4.296, \mathrm{P}=0.01$ ) were risk factors for postoperative recurrence of ovarian endometrioma, whereas postoperative pregnancy (HR: $0.361,95 \% \mathrm{Cl}: 0.138-0.944, \mathrm{P}=0.038$ ) was a protective factor for postoperative recurrence(Table 2). 
Table 2

Univariate and multivariate analysis of risk factors in the ovarian endometrioma recurrence and nonrecurrence groups

\begin{tabular}{|c|c|c|c|c|c|c|}
\hline \multirow[t]{2}{*}{ Fcator } & \multicolumn{3}{|c|}{ Univariate analysis } & \multicolumn{3}{|c|}{ Multivariate analysis } \\
\hline & $\begin{array}{l}\text { Hazard } \\
\text { ratio }\end{array}$ & $95 \% \mathrm{Cl}$ & $\mathrm{P}$ & $\begin{array}{l}\text { Hazard } \\
\text { ratio }\end{array}$ & $95 \% \mathrm{Cl}$ & $P$ \\
\hline Age (per year) & 0.955 & $\begin{array}{l}0.851- \\
1.071\end{array}$ & 0.429 & & & \\
\hline Menarche age (per year) & 1.039 & $\begin{array}{l}0.807- \\
1.338\end{array}$ & 0.767 & & & \\
\hline $\mathrm{CA} 125(\leq$ or $>35 \mathrm{U} / \mathrm{ml})$ & 3.207 & $\begin{array}{l}1.126- \\
9.135\end{array}$ & 0.029 & 1.993 & $\begin{array}{l}0.679- \\
5.844\end{array}$ & 0.209 \\
\hline $\begin{array}{l}\text { Preoperative } \\
\text { dysmenorrhoea }\end{array}$ & 1.262 & $\begin{array}{l}0.536- \\
2.972\end{array}$ & 0.594 & & & \\
\hline $\begin{array}{l}\text { Duration of } \\
\text { dysmenorrhoea(per m) }\end{array}$ & 1.009 & $\begin{array}{l}0.996- \\
1.022\end{array}$ & 0.171 & & & \\
\hline \multicolumn{7}{|l|}{ Extent of dysmenorrhoea } \\
\hline None & 1 & & & & & \\
\hline Mild & 0.855 & $\begin{array}{l}0.287- \\
2.55\end{array}$ & 0.779 & & & \\
\hline Moderate & 1.325 & $\begin{array}{l}0.531- \\
3.304\end{array}$ & 0.546 & & & \\
\hline Severe & 1.508 & $\begin{array}{l}0.584- \\
3.893\end{array}$ & 0.396 & & & \\
\hline $\begin{array}{l}\text { Postoperative } \\
\text { dysmenorrhoea }\end{array}$ & 2.465 & $\begin{array}{l}1.320- \\
4.604\end{array}$ & 0.005 & 2.291 & $\begin{array}{l}1.222- \\
4.296\end{array}$ & 0.01 \\
\hline Genital malformation & 0.646 & $\begin{array}{l}0.274- \\
1.522\end{array}$ & 0.318 & & & \\
\hline rAFS (I-II or III-IV) & 4.588 & $\begin{array}{l}1.422- \\
14.805\end{array}$ & 0.011 & 3.783 & $\begin{array}{l}1.162- \\
12.311\end{array}$ & 0.027 \\
\hline Cyst diameter (per 10mm) & 0.971 & $\begin{array}{l}0.876- \\
1.076\end{array}$ & 0.574 & & & \\
\hline Postoperative pregnancy & 0.28 & $\begin{array}{l}0.109- \\
0.723\end{array}$ & 0.008 & 0.361 & $\begin{array}{l}0.138- \\
0.944\end{array}$ & 0.038 \\
\hline Postoperative medication & 0.897 & $\begin{array}{l}0.457- \\
1.759\end{array}$ & 0.752 & & & \\
\hline
\end{tabular}




\section{Discussion}

In the present study, we analysed the risk factors for postoperative recurrence of ovarian endometrioma in young women. Endometriosis is a common gynaecological disease. Recently, the high postoperative recurrence rate of endometriosis and its related risk factors have been analysed and reported in an increasing number of retrospective and prospective studies. Ovarian endometrioma is the most common type of endometriosis. However, only a few studies have been conducted to asses the risk factors for postoperative recurrence of ovarian endometrioma in young women, and no risk factors associated with recurrence have been found. The present study focused on the risk factors associated with recurrence of ovarian endometrioma in young women.

Owing to the different criteria used to define postoperative recurrence endometrioma, its actual recurrence rate is not clear. Some authors consider the recurrence of symptoms as the recurrence of the disease. However, in most studies, the diagnosis of endometrioma was based on the results of ultrasound imaging. In addition, the recurrence rate was also affected by factors such as the severity of the disease, surgical technique used, duration of postoperative follow-up, postoperative intervention, and statistical methods used. The cumulative rate of postoperative recurrence of ovarian endometrioma over 5 years varies widely from $6.1-50 \%$ [2, 6-9]. In the present study, the cumulative five-year postoperative recurrence rate was $20.3 \%$.

Numerous previous studies have investigated risk factors for recurrence of ovarian endometrioma. Busacca et al. reported that rAFS disease stage was a risk factor for recurrence of ovarian endometrioma [10]. Chon et al. reported that dysmenorrhoea and inner cyst septation significantly affects the postoperative recurrence rate of ovarian endometrioma [11]. Selcuk et al. reported that the depth of endometrial tissue penetration into the ovarian cyst wall is an independent risk factor for recurrence [12]. Guzel et al. reported that CA125 levels, ovarian cyst size, and history of pelvic surgery affect the recurrence rate [13]. Moini et al. reported that large ovarian endometrioma is a high risk factor for postoperative recurrence [14]. However, it is difficult to compare the results of these studies due to differences in study population, duration of follow-up, and definition of recurrent ovarian endometrioma.

Most gynaecologists use the rAFS staging to describe the extent, depth, degree, and location of lesions in endometrioma. Tobiume et al. suggested that the rAFS disease stage is an independent risk factor for postoperative recurrence [8], whereas Porpora et al. believed that the rate of recurrence is higher in patients with late rAFS stage-disease [3]. Similar to the results of previous studies, we found that the rAFS disease stage was a risk factor for postoperative recurrence in the present study(Fig. 1A). The rAFS stage represents the extent of invasion by lesions and the severity of adhesions. The later the disease stage, the more difficult it is to completely eliminate the lesions, and the more prone the patient is to postoperative recurrence. Therefore, the postoperative recurrence of endometrioma can be predicted using the rAFS staging system.

Dysmenorrhoea is one of the most typical symptoms of ovarian endometrioma. The cause of dysmenorrhoea in ovarian endometrioma is not completely understood; however, it may occur in several 
ways. When abnormal endometrial tissue is present outside the uterus, periodic microbleeding within the endometrioma may cause severe dysmenorrhoea. The lesion activates a cascade of macrophages and cytokines that leads to a chronic inflammatory process that causes dysmenorrhoea [15]. The overexpression of local oestrogen receptors may also be a key factor in the severity of dysmenorrhoea [16]. Furthermore, endometrial lesions may infiltrate deeply into the intestines [17] and cause pelvic floor nerve entrapment and dysmenorrhoea [18]. The incidence of preoperative dysmenorrhoea in the present study was $83.2 \%$ and the median duration of dysmenorrhoea was five months. However, the duration and intensity of preoperative dysmenorrhoea had no effect on postoperative recurrence in the present study. Owing to the high incidence rate of dysmenorrhoea among young women with endometriosis, and given that some previous studies have demonstrated that the severity of preoperative dysmenorrhoea is a risk factor for postoperative recurrence [6], it is therefore recommended that if a patient experiences pain for 3-6 months, a more comprehensive assessment of chronic pelvic pain, including history taking and thorough physical examination, should be performed to assess the underlying cause of the pain. In the present study, postoperative dysmenorrhoea was a risk factor for postoperative recurrence of ovarian endometriosis(Fig. 1B), which is consistent with those of previous studies [19]. This suggests that close attention should be paid to dysmenorrhoea during postoperative follow-up. If dysmenorrhoea persists or worsens, further examination using ultrasound or pelvic magnetic resonance imaging is recommended to evaluate the potential causes of dysmenorrhoea.

Some previous studies have suggested that women who get pregnant postoperatively have a low recurrence rate of ovarian endometrioma, suggesting that postoperative pregnancy may have a protective effect on the recurrence of endometrioma [6,20-22]. Concordantly, the univariate analysis in our study shows that the postoperative pregnancy is significantly associated with endometrioma recurrence(Fig. 1C). Another study revealed a higher rate of spontaneous pregnancy in the first year after laparoscopic resection of the ovarian endometrioma [23]. Therefore, gynaecologists should provide active guidance for young women according to the patient's current and future pregnancy wishes. If the patient has a need for fertility after surgery, it is recommended that she try to get pregnant as early as possible after cystectomy.

The results of several multivariate analyses in previous studies have suggested that being too young at the time of surgery is a risk factor for recurrence of ovarian endometrioma $[14,22,24]$. A meta-analysis of 10 studies suggested that younger age might be a high-risk factor for the recurrence of ovarian endometrioma after conservative surgery [25]. In contrast, Parazzini suggested that older age is a risk factor for the recurrence of ovarian endometriosis [26]. The results of the present study suggest that the age at the time of surgery has no significant effect on the risk of recurrence. This may be related to the fact that all the patients enrolled in this study were young women.

We assessed the size of ovarian endometrioma in this study, and the results showed that cyst size has no effect on the recurrence of ovarian endometrioma. This finding is also consistent with those of previous studies $[3,6]$. However, in a multivariate analysis of women aged $40-49$ years, ovarian endometrioma larger than $5.5 \mathrm{~cm}$ was the only risk factor for postoperative recurrence [27]. The findings of some 
previous studies suggest that cyst size is a risk factor for recurrence of the disease $[14,20]$. These differences may be related to surgical experience, age of patients, and whether the tumour can be completely resected.

Serum CA125 level is currently the most commonly used marker for the assessment of endometrioma. However, only a few researchers have suggested that CA125 level is a risk factor for the recurrence of ovarian endometrioma [13]. In our series, log-rank test suggests women with preoperative serum CA125 over $35 \mathrm{U} / \mathrm{ml}$ had higher endometrioma recurrence rate(Fig. 1D), however, the result of Cox proportional hazard regression model, which suggests that preoperative serum CA125 level is not an independent risk factor for postoperative ectopic recurrence, is consistent with those of most studies(Fig. 1F). Due to the limited diagnostic accuracy and low sensitivity of CA125, its accuracy in predicting recurrence of endometrioma is limited.

In the present study, GnRH-a was administered for 3-6 months after surgery. We found that postoperative $\mathrm{GnRH}$-a treatment did not significantly reduce the recurrence rate of endometrioma, which is consistent with those of previous studies [27, 28], Muzii reported that preoperative administration of GnRH-a for three months did not significantly reduce the postoperative recurrence rate of ovarian endometrioma [29]. The results of the present study did not indicate that perioperative use of $\mathrm{GnRH}-\mathrm{a}$ is beneficial for the prevention of postoperative recurrence. Due to the high cost of $\mathrm{GnRH}-\mathrm{a}$ drugs and a series of side effects such as osteoporosis and perimenopause-related symptoms caused by long-term use, other effective drugs have been promoted instead. Takamura found that oral contraceptive treatment for 24 months after laparoscopic resection of ovarian endometrioma is effective in preventing postoperative recurrence of ovarian endometrioma [30]. A retrospective study of 362 women of reproductive age who underwent laparoscopic surgery for endometrioma showed that postoperative $\mathrm{GnRH}-\mathrm{a}$ combined with cyclic oral contraceptives significantly reduced the five-year postoperative recurrence rate of endometrioma compared with $\mathrm{GnRH}-\mathrm{a}$ alone [9]. Another meta-analysis revealed that patients who received dienogest after conservative surgery for endometriosis had a significantly lower risk of postoperative disease recurrence than those who were expectantly managed [31]. However, the results of the present study did not show that oral contraceptives alone or combined with $\mathrm{GnRH}$-a could reduce the postoperative recurrence rate of endometrioma. This may be related to the small number of patients who took oral drugs in this study. Future studies with larger sample sizes are necessary to verify this finding.

The recommended treatment for endometriosis in adolescents is conservative surgical therapy in combination with continuous suppressive medication[32]. Surgical treatment for endometriosis includes laparotomy and laparoscopy. However, laparoscopy has become the preferred surgical method for the treatment of endometriosis due to its advantages, including prevention of adhesion, less intraoperative blood loss, early postoperative exhaust, short duration of postoperative fever, and quick recovery. The proportion of laparoscopy cases in the present study was $90.3 \%$.

The advantages of this study are that the follow-up duration was more than three years, the clinical data was documented in detail, and the sample size is large. However, the study contains some limitations. 
First, this was a retrospective case-control study, patients from two regional medical center hospitals were selected as subjects, due to the high proportion of combined genital malformation, there may be bias in selection. Second, patients with severe endometriosis may be more inclined to receive preoperative medication, but this study failed to collect preoperative medication data, which may have a potential impact on the study results. Finally, determination of disease recurrence was based on an ultrasound diagnosis, which depends on the sonographer's skill and experience. These limitations can cause correlations to be underestimated or overestimated.

In conclusion, we conducted a long-term follow-up study for more than 3 years to investigate the risk factors for postoperative recurrence of ovarian endometrioma in young women. Our results showed that the rAFS disease stage and postoperative dysmenorrhoea are independent risk factors for recurrence of ovarian endometrioma, whereas postoperative pregnancy is a protective factor for recurrence. For young patients who have severe disease or who still have dysmenorrhoea after surgery, greater attention should be paid to the risk of postoperative recurrence. Those who are willing to get pregnant should be guided to actively prepare for pregnancy and undergo individualised treatment to obtain better curative effects.

\section{Declarations}

\section{Ethics approval}

The study was approved by the Ethics Committee of Peking Union Medical College Hospitalthe (JS-1804) and Shengjing Hospital of China Medical University (2019PS015F) and conducted in accordance with the Declaration of Helsinki.

\section{Consent to participate}

Written informed consent was obtained from individual or guardian participants.

\section{Consent for publication}

All the authors in this paper consent to publication of the work.

\section{Availability of data and material}

The datasets used and/or analyzed during the current study are available from the corresponding author on reasonable request.

\section{Competing interests}


The authors declare that they have no competing interests.

\section{Funding}

This work was supported by the National Key Research and Development Program (2018YFC1002105).

\section{Authors' contributions}

JCT designed the study. XX performed the study and wrote the paper. XCS, XYZ, SSW, JRQ, XYH, AXS and ZFM contributed to the data collecting. All authors read and approved the fnal manuscript.

\section{Acknowledgments}

We appreciate the staff at Peking Union Medical College Hospital and Shengjing Hospital for their diligent clinical work and for recording accurate case data as reported in this article.

\section{References}

1. Guo S.W. Recurrence of endometriosis and its control. Hum Reprod Update. 2009; 15(4): 441-61.

2. Lee S.Y., Kim M.L., Seong S.J., Bae J.W., and Cho Y.J. Recurrence of Ovarian Endometrioma in Adolescents after Conservative, Laparoscopic Cyst Enucleation. J Pediatr Adolesc Gynecol. 2017; 30(2): 228-33.

3. Porpora M.G., Pallante D., Ferro A., Crisafi B., Bellati F., and Benedetti P.P. Pain and ovarian endometrioma recurrence after laparoscopic treatment of endometriosis: a long-term prospective study. Fertil Steril. 2010; 93(3): 716-21.

4. Revised American Society for Reproductive Medicine classification of endometriosis: 1996. Fertil Steril. 1997; 67(5): 817-21.

5. Mais V., Guerriero S., Ajossa S., Angiolucci M., Paoletti A.M., and Melis G.B. The efficiency of transvaginal ultrasonography in the diagnosis of endometrioma. Fertil Steril. 1993; 60(5): 776-80.

6. Li X.Y., Chao X.P., Leng J.H., Zhang W., Zhang J.J., and Dai Y., et al. Risk factors for postoperative recurrence of ovarian endometriosis: long-term follow-up of 358 women. J Ovarian Res. 2019; 12(1): 79.

7. Fedele L., Bianchi S., Zanconato G., Berlanda N., Raffaelli R., and Fontana E. Laparoscopic excision of recurrent endometriomas: long-term outcome and comparison with primary surgery. Fertil Steril. 2006; 85(3): 694-9.

8. Tobiume T., Kotani Y., Takaya H., Nakai H., Tsuji I., Suzuki A., and Mandai M. Determinant factors of postoperative recurrence of endometriosis: difference between endometrioma and pain. Eur $\mathrm{J}$ Obstet Gynecol Reprod Biol. 2016; 205: 54-9. 
9. Lee D.Y., Bae D.S., Yoon B.K., and Choi D. Post-operative cyclic oral contraceptive use after gonadotrophin-releasing hormone agonist treatment effectively prevents endometrioma recurrence. Hum Reprod. 2010; 25(12): 3050-4.

10. Busacca M., Marana R., Caruana P., Candiani M., Muzii L., Calia C., and Bianchi S. Recurrence of ovarian endometrioma after laparoscopic excision. Am J Obstet Gynecol. 1999; 180(3 Pt 1): 519-23.

11. Chon S.J., Lee S.H., Choi J.H., and Lee J.S. Preoperative risk factors in recurrent endometrioma after primary conservative surgery. Obstet Gynecol Sci. 2016; 59(4): 286-94.

12. Selcuk S., Cam C., Koc N., Kucukbas M., Ozkaya E., Eser A., and Karateke A. Evaluation of risk factors for the recurrence of ovarian endometriomas. European Journal of Obstetrics \& Gynecology and Reproductive Biology. 2016; 203: 56-60.

13. Guzel A.I., Topcu H.O., Ekilinc S., Tokmak A., Kokanali M.K., Cavkaytar S., and Doganay M. Recurrence factors in women underwent laparoscopic surgery for endometrioma. Minerva Chir. 2014; 69(5): 27782.

14. Moini A., Arabipoor A. and Ashrafinia N. Risk factors for recurrence rate of ovarian endometriomas following a laparoscopic cystectomy. Minerva Med. 2014; 105(4): 295-301.

15. Bedaiwy M.A., Hussein M.R., Biscotti C., and Falcone T. Pelvic endometriosis is rarely associated with ovarian borderline tumours, cytologic and architectural atypia: a clinicopathologic study. Pathol Oncol Res. 2009; 15(1): 81-8.

16. Pluchino N., Mamillapalli R., Wenger J.M., Ramyead L., Drakopoulos P., Tille J.C., and Taylor H.S. Estrogen receptor-alpha immunoreactivity predicts symptom severity and pain recurrence in deep endometriosis. Fertil Steril. 2020; 113(6): 1224-31.

17. Abrao M.S., Petraglia F., Falcone T., Keckstein J., Osuga Y., and Chapron C. Deep endometriosis infiltrating the recto-sigmoid: critical factors to consider before management. Hum Reprod Update. 2015; 21(3): 329-39.

18. Medina M.G. and Lebovic D.I. Endometriosis-associated nerve fibers and pain. Acta Obstet Gynecol Scand. 2009; 88(9): 968-75.

19. Han S., Lee H., Kim S., Joo J., Suh D., Kim K., and Lee K. Risk factors related to the recurrence of endometrioma in patients with long-term postoperative medical therapy. Ginekol Pol. 2018; 89(11): 611-7.

20. Koga K., Takemura Y., Osuga Y., Yoshino O., Hirota Y., and Hirata T., et al. Recurrence of ovarian endometrioma after laparoscopic excision. Human Reproduction. 2006; 21(8): 2171-4.

21. Wacharachawana S., Phaliwong P., Prommas S., Smanchat B., Bhamarapravatana K., and Suwannarurk K. Recurrence Rate and Risk Factors for the Recurrence of Ovarian Endometriosis after Laparoscopic Ovarian Cystectomy. Biomed Res Int. 2021; 2021: 6679641.

22. Sengoku K., Miyamoto T., Horikawa M., Katayama H., Nishiwaki K., and Kato Y., et al. Clinicopathologic risk factors for recurrence of ovarian endometrioma following laparoscopic cystectomy. Acta Obstet Gynecol Scand. 2013; 92(3): 278-84. 
23. Alborzi S., Momtahan M., Parsanezhad M.E., Dehbashi S., Zolghadri J., and Alborzi S. A prospective, randomized study comparing laparoscopic ovarian cystectomy versus fenestration and coagulation in patients with endometriomas. Fertil Steril. 2004; 82(6): 1633-7.

24. Kikuchi I., Takeuchi H., Kitade M., Shimanuki H., Kumakiri J., and Kinoshita K. Recurrence rate of endometriomas following a laparoscopic cystectomy. Acta Obstet Gynecol Scand. 2006; 85(9): 11204.

25. Yang F., Liu B., Xu L., and Liu H. Age at surgery and recurrence of ovarian endometrioma after conservative surgery: a meta-analysis including 3125 patients. Arch Gynecol Obstet. 2020; 302(1): 23-30.

26. Parazzini F., Bertulessi C., Pasini A., Rosati M., Di Stefano F., and Shonauer S., et al. Determinants of short term recurrence rate of endometriosis. Eur J Obstet Gynecol Reprod Biol. 2005; 121(2): 216-9.

27. Lee N., Min S., Won S., Cho Y.J., Kim M., and Kim M.K., et al. The recurrence rate of ovarian endometrioma in women aged 40-49 years and impact of hormonal treatment after conservative surgery. Sci Rep. 2020; 10(1): 16461.

28. Busacca M., Somigliana E., Bianchi S., De Marinis S., Calia C., Candiani M., and Vignali M. Postoperative $\mathrm{GnRH}$ analogue treatment after conservative surgery for symptomatic endometriosis stage III-IV: a randomized controlled trial. Hum Reprod. 2001; 16(11): 2399-402.

29. Muzii L., Marana R., Caruana P., and Mancuso S. The impact of preoperative gonadotropin-releasing hormone agonist treatment on laparoscopic excision of ovarian endometriotic cysts. Fertility and sterility. 1996; 65(6): 1235-7.

30. Takamura M., Koga K., Osuga Y., Takemura Y., Hamasaki K., and Hirota Y., et al. Post-operative oral contraceptive use reduces the risk of ovarian endometrioma recurrence after laparoscopic excision. Hum Reprod. 2009; 24(12): 3042-8.

31. Zakhari A., Edwards D., Ryu M., Matelski J.J., Bougie O., and Murji A. Dienogest and the Risk of Endometriosis Recurrence Following Surgery: A Systematic Review and Meta-analysis. J Minim Invasive Gynecol. 2020; 27(7): 1503-10.

32. ACOG Committee Opinion No. 760: Dysmenorrhea and Endometriosis in the Adolescent. Obstet Gynecol. 2018; 132(6): e249-58.

\section{Figures}



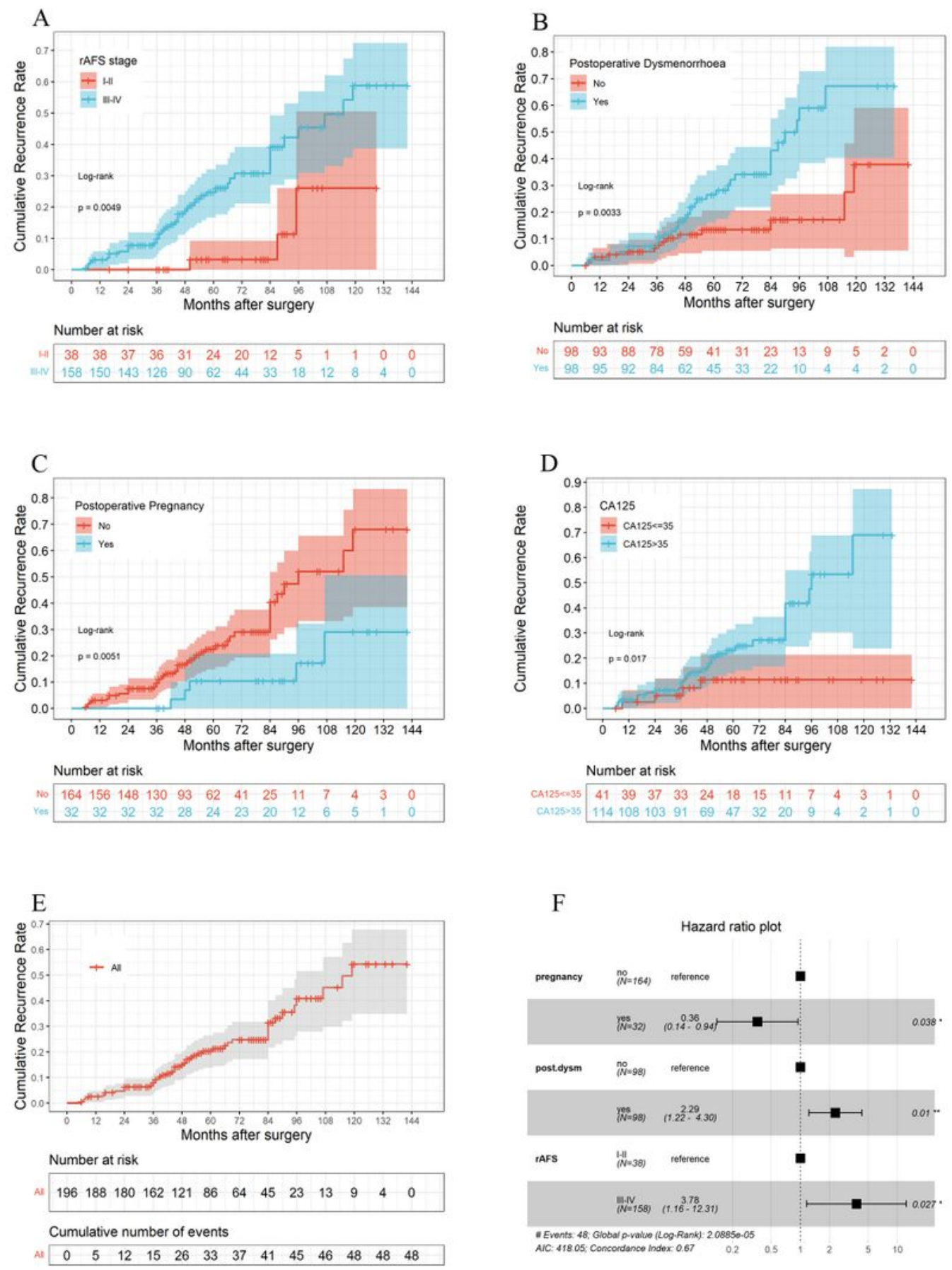

\section{Figure 1}

1A Kaplan-Meier curves presenting the cumulative recurrence rate according to the rAFS stage. There were significant differences between the two groups according to the log-rank test analysis $(X 2=7.915, p$ $=0.005)$. 1B Kaplan-Meier curves presenting the cumulative recurrence rate according to the Postoperative dysmenorrhoea. There were significant differences between the two groups according to the log-rank test analysis $(\chi 2=8.629, p=0.003)$. $1 \mathrm{C}$ Kaplan-Meier curves presenting the cumulative 
recurrence rate according to the Postoperative pregnancy. There were significant differences between the two groups according to the log-rank test analysis $(\chi 2=7.857, p=0.005)$. 1D Kaplan-Meier curves presenting the cumulative recurrence rate according to the CA125. There were significant differences between the two groups according to the log-rank test analysis $(\chi 2=5.77, p=0.017) .1 \mathrm{E}$ Cumulative recurrence rate in 196 young women who underwent conservative surgery for ovarian endometrioma. $1 \mathrm{~F}$ Multivariable predictor of postoperative recurrence of ovarian endometrioma. 